\title{
Confocal Raman Microscopy: Tablet Mapping Application for the Pharmaceutical Industry
}

\author{
Renan Marcel Bonilha Dezena ${ }^{1 *} \mathbb{D}$ José dos Santos Malta Júnior², Fabio Preto de \\ Godoy ${ }^{3}$, Tim Smith ${ }^{3}$ \\ ${ }^{1}$ Preformulation Specialist in the Pharmaceutical Industry, Brazil \\ ${ }^{2}$ Instituto Vita Nova, Rua Barão de Itapura, 135, Hortolândia, 13.186-481, SP, Brazil \\ ${ }^{3}$ Renishaw Company, Calçada dos Cravos 141, C.C. Alphaville, Barueri, 06453-053, SP, Brazil
}

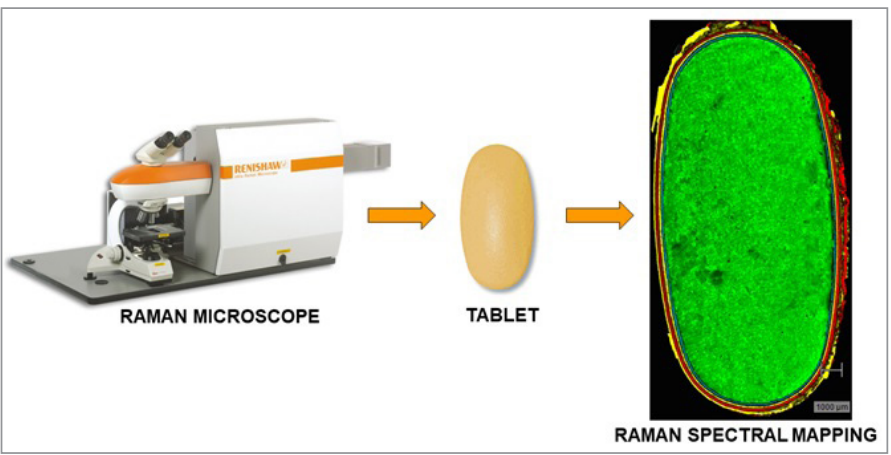

\section{Background}

In the United States of America (USA), more than 15 million people perform medical treatments every day using non-steroidal anti-inflammatory drugs (NSAIDs) for pain or inflammation. Although NSAIDs are widely considered effective substances in medical clinics, their administration may lead to the development of gastroduodenal lesions, such as ulcers and erosions [1-5].

Over time, one of the strategies implemented to reduce the gastrointestinal risk associated with the intake of NSAIDs is the prescription of drugs that inhibit stomach acid secretion, ie, the pharmacological class of proton pump inhibitors [1-5]. In addition, the World Health Organization (WHO) classifies chronic inflammatory diseases as a major threat to human health [1-5]. Thus, focusing on improving tolerability to NSAIDs formulations by combining esomeprazole magnesium and naproxen, producing the desired pharmacodynamic response, is becoming more common in the pharmaceutical industry [1-5].

Applying preformulation studies in the early stages of the development of a reference product or generic product enables better knowledge focused on both the optimised manufacturing process and the high potential for clinical success [6-12]. Therefore, an effective strategy is based on the characterisation of the active pharmaceutical ingredient (API) and excipients, providing insight into the physicochemical properties such as incompatibilities, detection of impurities, polymorphic transitions and design of formulations with a pharmacological approach in which esomeprazole magnesium could be added in the coating of the tablet it would be released first in the stomach to reduce the amount of acid produced, while naproxen protected by a layer of excipient resistant to the acidic environment of the stomach, could be released in the small intestine, thus reducing possible damage to the stomach by its action, so contributing only to its therapeutic anti-inflammatory, analgesic and antipyretic effect [6-12]. One of the biggest challenges in the formulation design is to achieve stability in the finished product; therefore, it is important to study the compatibility between more than one API when there is an association in the product beyond the excipients used in the formulation. This enables the selection of the most stable pharmaceutical composition [6-12]. 
Chandrasekhara Venkata Raman was an Indian physicist who was awarded the 1930 Nobel Prize in physics for his work on light scattering and the discovery of the Raman Effect [13-20]. When the incidence of photons occurs in a sample, there is a loss or gain of energy. The loss of energy of the incident photon is a stronger effect, and this phenomenon is known as Stokes scattering. In contrast, when the incident photons gain energy, this is known as anti-Stokes scattering [13-20]. Within the pharmaceutical industry, almost all samples have spectra that follow Stoke dispersion, which mainly involves the vibrational modes of the molecules [13-20].

Confocal Raman microscopy (CRM) technology is a powerful ally in the development of pharmaceutical compositions through the investigation of the chemical composition of a sample and the particle size distribution of the components in the formulations and through the characterisation of the homogeneity of the products and the interaction of active substances and excipients. The chemical information obtained by CRM is also useful for the design of new molecules for the development of solids, semi-solids, and liquids, contributing to a comprehensive understanding of a pharmaceutical product and its development [21].

\section{Raman Imaging}

A Renishaw inVia Confocal Raman Microscope equipped with $785 \mathrm{~nm}$ laser excitation and StreamLine ${ }^{\mathrm{TM}}$ fast imaging capability was used to analyse and compare reference and generic tablets.

Reference samples were supplied. Raman spectra were collected from the majority of references (especially the API species) for the purpose of generating chemical images of the different species. Some excipient spectra were used from the Renishaw excipient database.

StreamLine imaging was used to produce Raman map data from the sectioned surface of the tablets. Data was collected from both a small region around the coating ( $3.5 \mu \mathrm{m}$ step size) and the entire surface (35.5 $\mu \mathrm{m}$ step size). This provides an ideal balance of high-resolution coating analysis and context with the entire section.

Spectral map data was analysed using a direct classical least-squares method incorporating the reference spectra to produce chemical images of the different species.

For each sample, the chemical images were analysed and compared to provide conclusions and answers to the questions posed regarding the location of specific species.

The tablet was held on a metal microscope slide, and the surface was milled to approximately the centre of the tablet. The specific conditions for collecting map data are shown in Table I.

Equivalent conditions were used between the reference and generic tablets.

Table I: The specific map data collection conditions.

\begin{tabular}{lcc}
\hline Raman microscope & Coating targeted & Entire surface \\
\hline Wavelength & \multicolumn{2}{c}{$785 \mathrm{~nm}$} \\
Laser power & $50 \%$ \\
Grating & $1200 \mathrm{l} / \mathrm{mm}\left(1 \mathrm{~cm}^{-1}\right.$ spectral resolution $)$ \\
Objective & $20 \times$ \\
Scan type & \multicolumn{2}{c}{ StreamLine ${ }^{\mathrm{TM}}$ imaging } \\
Purpose of scan & Domain size and distribution of API species \\
Total time & 39 minutes & 61 minutes \\
Area & $595 \mu \mathrm{m}(\mathrm{x}) \times 780.5 \mathrm{~mm}(\mathrm{y})$ & $9.017 \mathrm{~mm}(\mathrm{x}) \times 9.336 \mathrm{~mm}(\mathrm{y})$ \\
Step size & $3.5 \mu \mathrm{m}$ & $35.5 \mu \mathrm{m}$ \\
No of spectra & 37,910 & 66,802 \\
\hline
\end{tabular}




\section{Comparing the Reference Product and Generic Product}

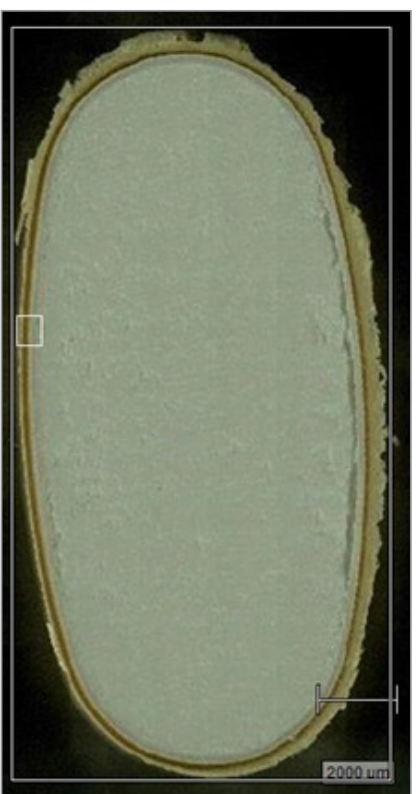

Figure 1. White light montage of the generic tablet.

White light images (montages) of the entire tablet surface were collected and are shown in Figure 1. This makes determination of the context of the analysis locations against the size of the entire sample surface simple (the inset white boxes indicate the analysed areas). Multiple analysis regions can be defined from the same montage and queued to run concurrently.

The Raman images confirm that there are four layers represented in Figure 2. A species similar to esomeprazole magnesium was found in layer 2. Naproxen was found in the core and within layer 4.

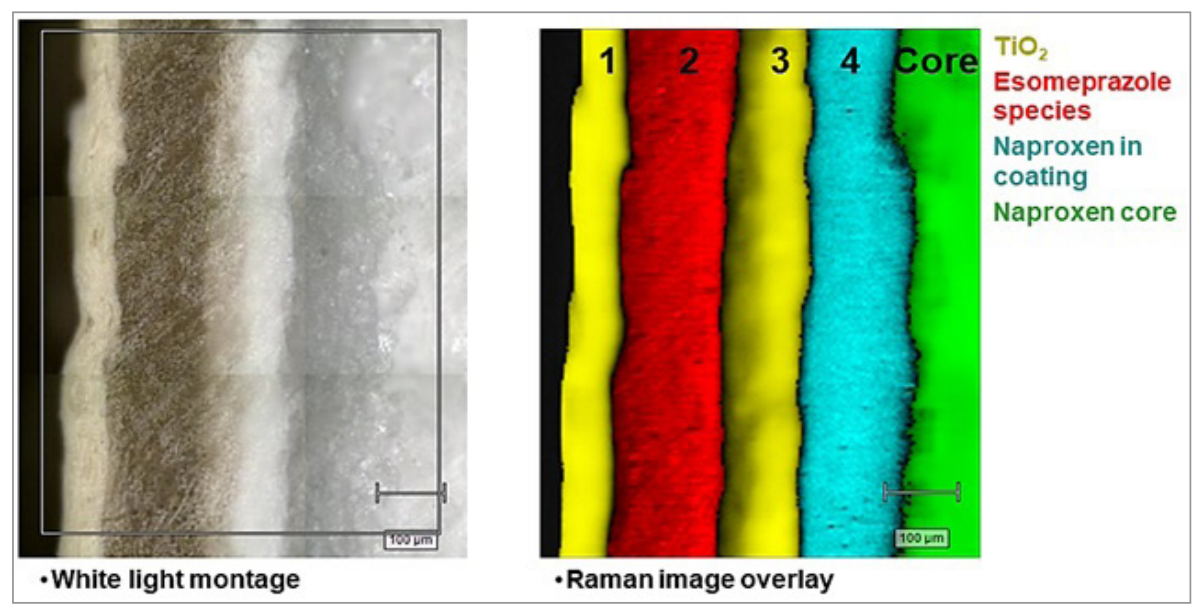

Figure 2. Raman images of the coating region and core of the generic tablet.

As shown in Figure 3, the esomeprazole magnesium Raman spectrum is not identical to the reference spectrum, suggesting that the esomeprazole magnesium exists in the coating as a different form/ hydrate. In fact, the esomeprazole magnesium presents pseudopolymorphism, that is, a difference in the crystallographic profile due to a difference in the degree of hydration (anhydrous, dihydrate, and trihydrate forms are available) [22]. The reference spectrum corresponds to the esomeprazole magnesium trihydrate form (CAS Number 217087-09-7).

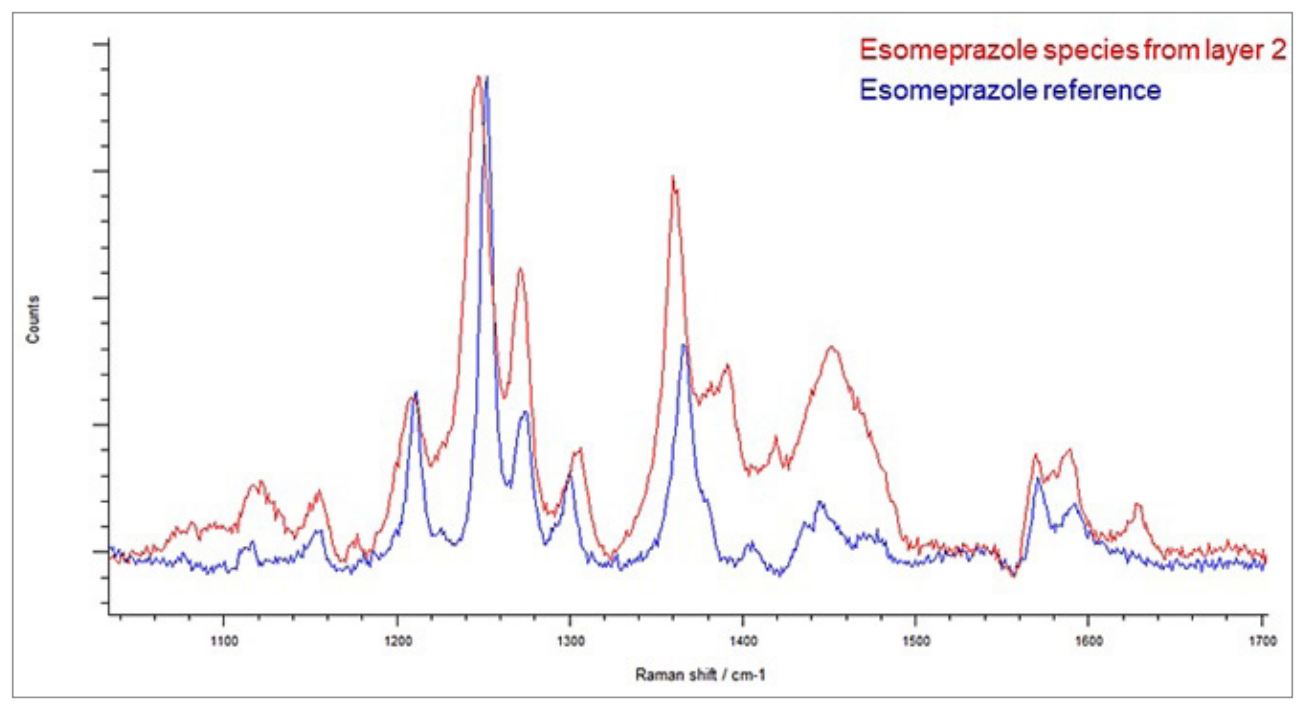

Figure 3. Raman spectra of the layer 2 of the generic tablet. 
The difference found would be justified because the generic product most likely used an organic solvent to incorporate the API into the coating, producing a solvate, or caused desolvation, reducing the degree of hydration of esomeprazole magnesium from trihydrate to dihydrate or anhydrous forms.

The naproxen Raman spectra are identical to the reference. The presence of increased background and other Raman band features enables the naproxen coating to be differentiated from the naproxen core (Figure 4).

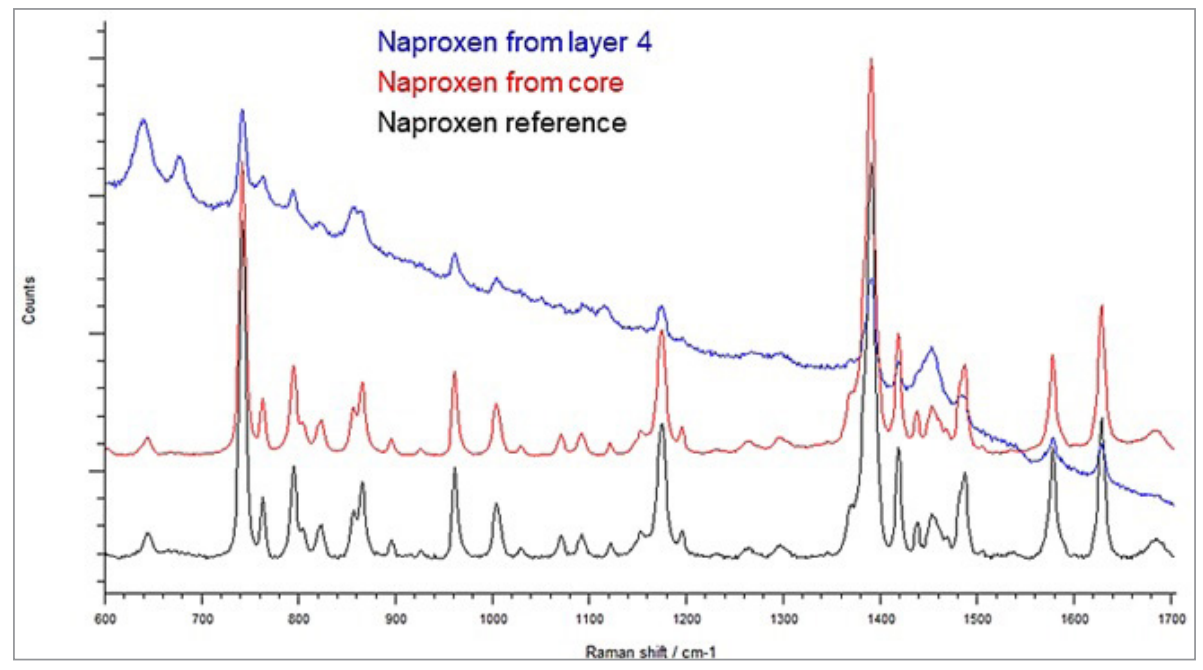

Figure 4. Raman spectra of the layer 4 of the generic tablet.

Analysis of the entire section shows that the core is made predominantly of naproxen. During the sample preparation stage (milling), some parts of the coating became fragmented. The left and lower regions are believed to best represent the real coating. A comparison of the coating regions, collected at the different spatial resolutions, is shown in Figure 5.

Figure 6 shows that both images reveal the same number of layers with the same content. Using a smaller step size from $35.5 \mu \mathrm{m}$ to $3.5 \mu \mathrm{m}$ which is smallest spacing between acquisition points on the sample, increases the spatial resolution, enabling more detail to be seen.

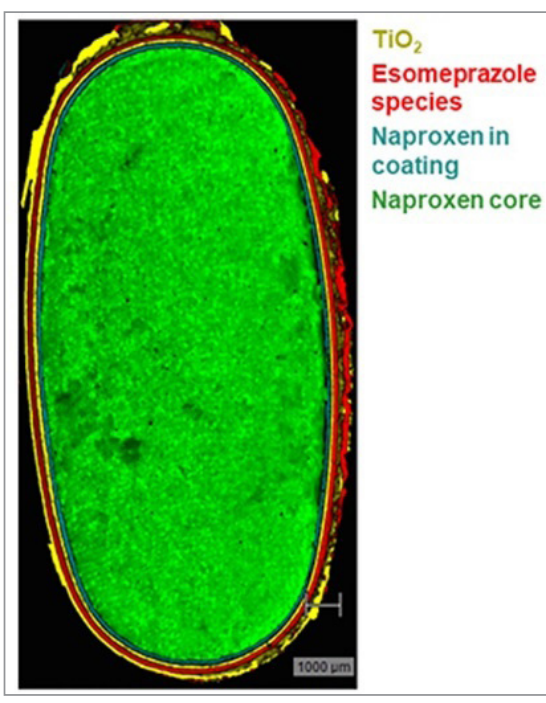

Figure 5. Raman images of the entire section of the generic tablet.

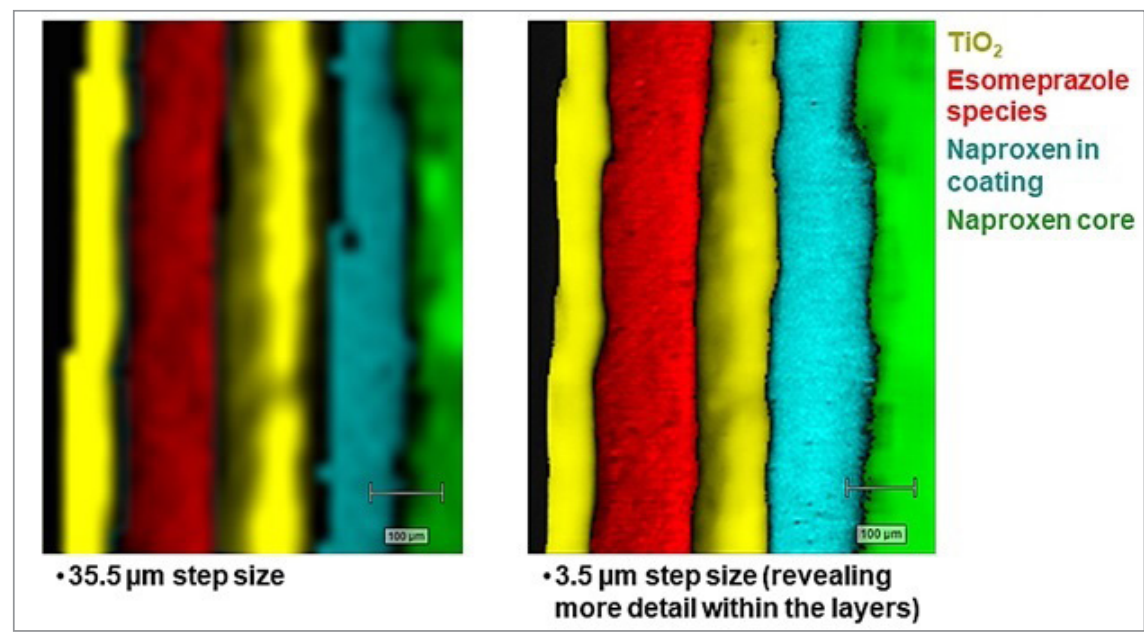

Figure 6. Raman images of the coating region and core of the generic tablet with $35.5 \mu \mathrm{m}$ versus $3.5 \mu \mathrm{m}$ of step size. 
Raman images were produced in the same way for the reference tablet. The coating images confirm that there are four layers, equivalent to that of the generic sample, shown in Figure 7. The esomeprazole magnesium found in layer 2 exactly matches the supplied reference material (unlike the generic product). Naproxen was found in the core and within layer 4, and this species was equivalent between samples and the reference material.

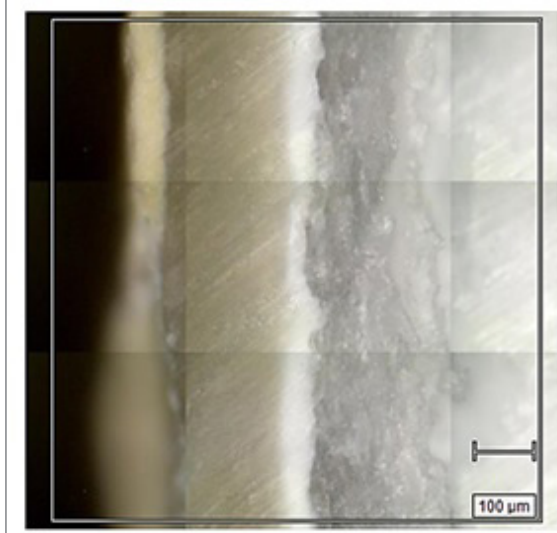

-White light montage
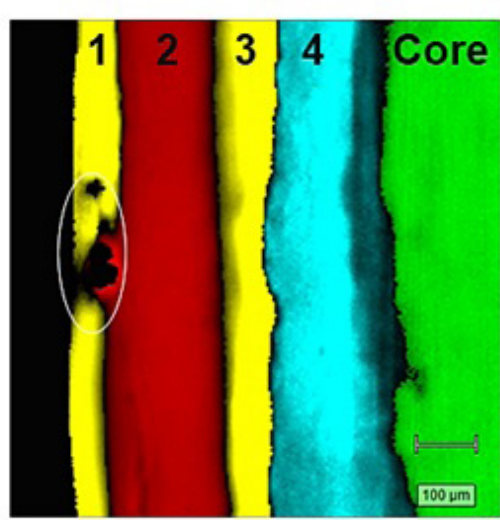

- Raman image overlay
$\mathrm{TiO}_{2}$

Esomeprazole Naproxen in coating Naproxen core (Minor coating defect or laser damage circled)

Figure 7. Raman images of the coating region and core of the reference tablet.

Figure 8 shows that the esomeprazole magnesium Raman spectrum is equivalent to the reference (with the addition of some coating excipients) and different from the generic product. Analysis of the entire section showed that the core is made predominantly of naproxen.

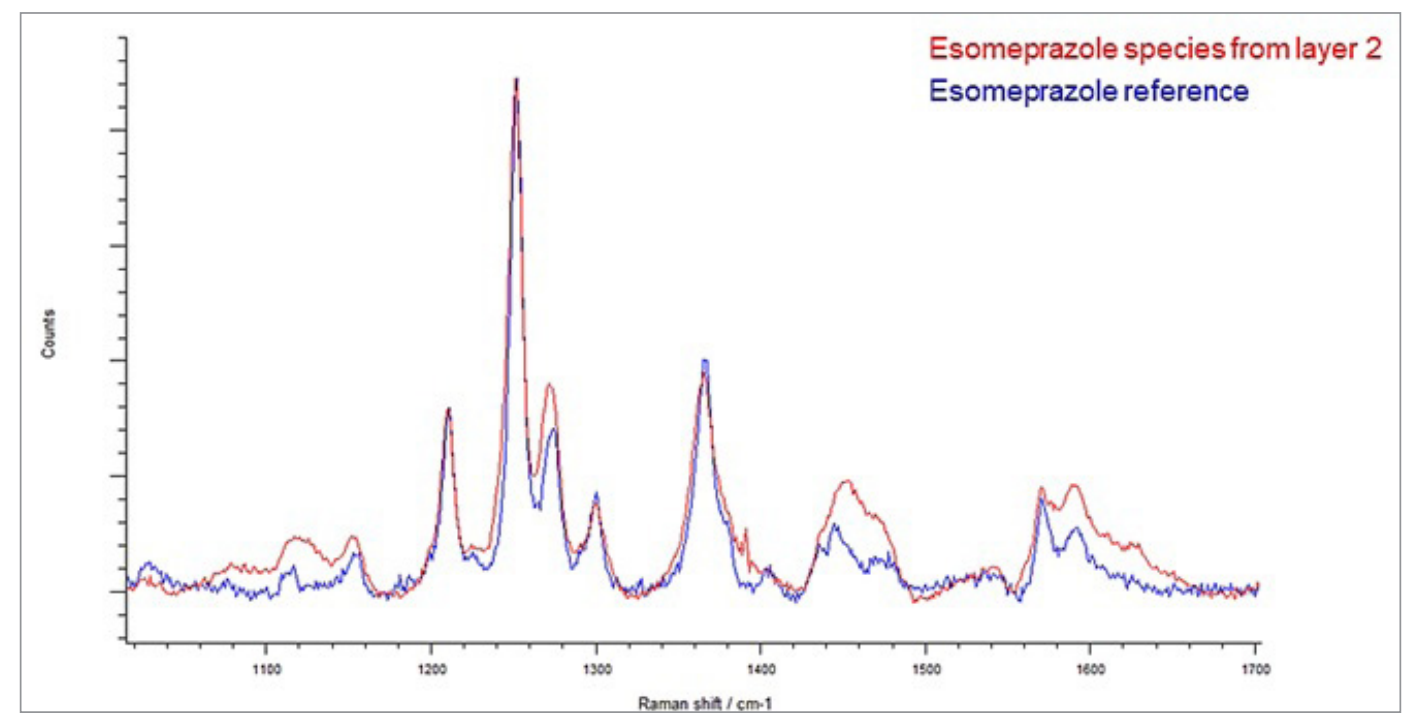

Figure 8. Raman spectra of the layer 2 of the reference tablet.

A comparison of the coating regions collected at the different spatial resolutions is shown in Figure 9.

Both images reveal the same number of layers with the same content. Using a smaller step size from $35.5 \mu \mathrm{m}$ to $3.5 \mu \mathrm{m}$ which is smallest spacing between acquisition points on the sample, increases the spatial resolution, enabling more detail to be seen in Figure 10.

Generally, both samples exhibit the same number of coatings, similar coating thicknesses, and the same constituents (excipient species were not specifically targeted in this work), according to Figure 11. The only significant difference observed was the form of the esomeprazole magnesium species. This 
species matched the pure reference and the reference tablet and was different from the generic product.

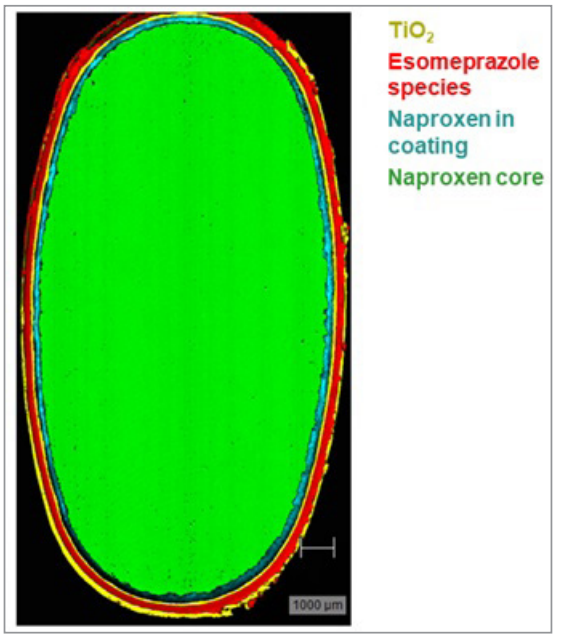

Figure 9. Raman images of the entire section of the reference tablet.

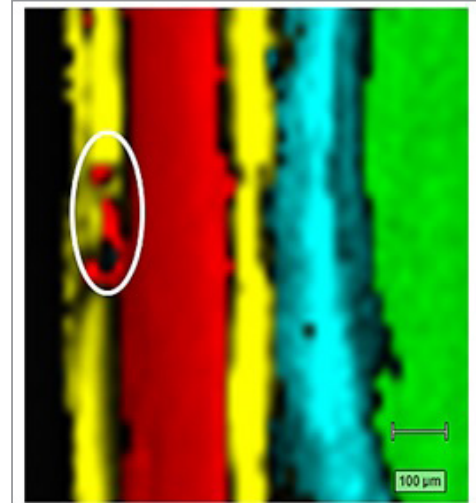

$\cdot 35.5 \mu \mathrm{m}$ step size

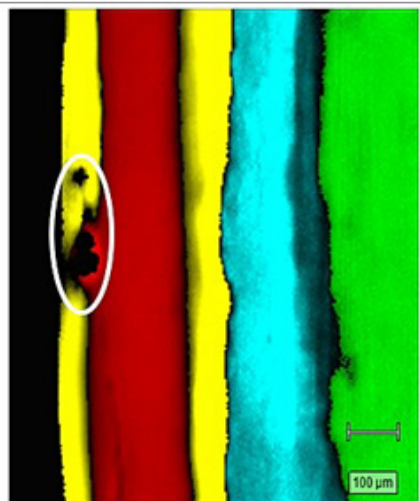

-3.5 $\mu \mathrm{m}$ step size (revealing more detail within the layers)
$\mathrm{TiO}_{2}$

Esomeprazole Naproxen in coating

Naproxen core

(Minor coating defect or laser damage circled)

Figure 10. Raman images of the coating region and core of the reference tablet with $35.5 \mu \mathrm{m}$ versus $3.5 \mu \mathrm{m}$ of step size.

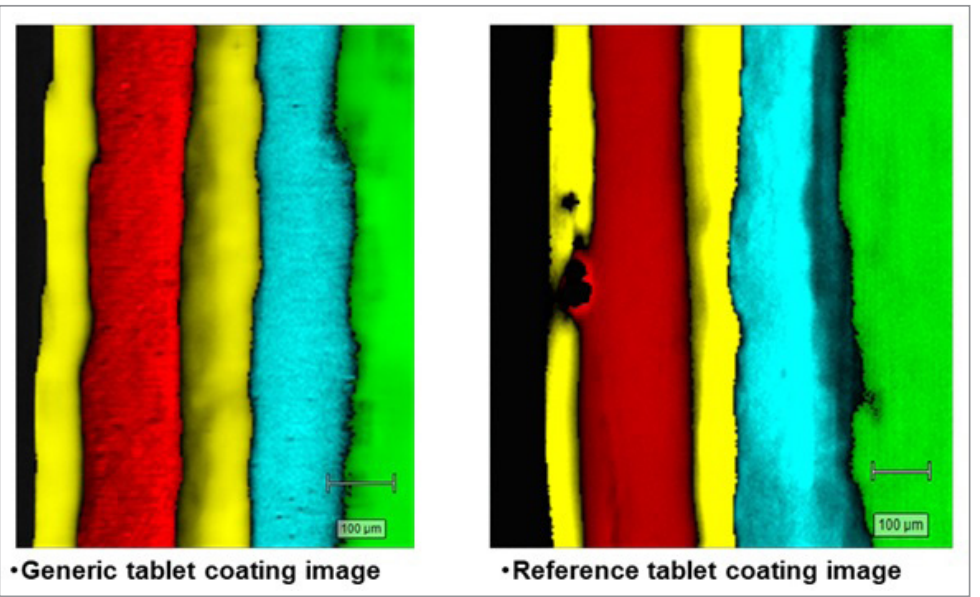

Figure 11. Raman images of the coating region and core of the generic tablet versus reference tablet.

\section{Summary}

The inVia Confocal Raman Microscope was used to analyse and compare two different pharmaceutical tablets, showing how this instrument can be applied in real-world scenarios in the development of pharmaceutical formulations. Raman imaging was used to create high-quality data from which detailed chemical images could be produced. inVia was capable of imaging the tablets at a variety of different spatial resolutions. The $20 \times$ objective is ideal for tablet imaging since it can provide a range of spatial resolution values (ranging from $\sim 3 \mu \mathrm{m}$ to greater than $100 \mu \mathrm{m}$ ). This is achieved by analysing the same sample depth, enabling simple image comparison.

In particular, the component analysis method enables images to be generated very quickly, targeting specific components, with the ability to reveal 'unknown' species for subsequent work. The high specificity and sensitivity of this method enables different forms of species to be revealed, as well as the generation of detailed chemical images. 
The following questions were answered during this analysis, showing the value of the Raman microscope as a tool for product analysis and comparison:

i. Determine the layer(s) that contains esomeprazole magnesium.

Both samples have this present in only one layer. The forms of esomeprazole magnesium appear different between the samples.

ii. Confirm the number of layers since there are some differences in the literature.

Both samples have four clear layers surrounding the core.

iii. Determine the composition of the different layers.

The API species within the layers and the core were determined. Coating thicknesses could be established. Some excipient species were also found; although, this work did not specifically analyse these.

iv. Determine the particle size of naproxen, esomeprazole magnesium, and the major excipients. Domain sizes are typically quantified using particle statistics with Renishaw WiRE software. Raman images are required to show discrete domains of each species to enable such quantification. In both samples, no discrete API domains were found to enable such particle analysis. The core is primarily comprised of naproxen, which practically forms one continuous domain. The coatings appear relatively homogenous, with no apparent separation of the API species into discrete domains.

v. Map the distribution of the API and excipients across the different layers.

The API species are uniformly distributed in the relevant coatings for both tablets supplied.

vi. Compare the distribution of the reference product core with the generic product core. No differences were observed between the tablet cores.

vii. Compare the polymorphic form of esomeprazole magnesium and naproxen used in the reference product with the reference APIs. Check the hydration state of both APIs.

The naproxen spectra appear the same between the different tablets and match the reference naproxen supplied. The spectrum of the esomeprazole magnesium in the generic tablet was different from the reference tablet and the supplied reference material. This most likely results from a change in polymorphic form/hydration state.

\section{References}

1. Plachetka, J. R.; Hill C. US0172983 A1, July 8, 2010, NC (US).

2. Anderson, D.; Gandhi, T.; Caspi, A. The Product Profiler, 2010, 35 (9), pp 1-19.

3. Weckwerth, G. M.; Simoneti, L. F.; Gonçalves, P. Z.; Calvo, A. M.; Brozoski, D. T.; Dionísio, T. J.; Torres, E. A.; Lauris, J. R. P.; Faria, F. A. C.; Santos,C. F. Med Oral Patol Oral Cir Bucal., 2017, 22 (1), pp 122-131 (http://dx.doi.org/doi:10.4317/medoral.21514).

4. Pahwa, R.; Singh, A.; Jialal, I. Chronic Inflammation [Updated 2019 Dec 13]. In: StatPearls [Internet]. Treasure Island (FL): StatPearls Publishing; 2019, January.

5. Steinmeyer, J. Arthritis Res., 2000, 2 (5), pp 379-385 (https://doi.org/10.1186/ar116).

6. Siew, A. Pharm. Technol., 2017, 41 (10), pp 20-27.

7. Desu, P. K.; Vaishnavi, G.; Divya, K.; Lakshmi, U. Indo Am. J. Pharm. Sci., 2015, 2 (10), pp 13991407.

8. Sahitya, G.; Krishnamoorthy, B.; Muthukumaran, M. Int. J. Pharm. Technol., 2013, 4 (4), pp 2311 2331.

9. Kulkarni, S.; Sharma, S. B.; Agrawal, A. Int. J. Pharm., Chem. Biol. Sci., 2015, 5 (2), pp 403-406.

10. Gore, S. S.; Jagdale, S. C.; Kuchekar, B. S. Int J Pharma Sci., 2014, 4 (5), pp 707-712.

11. Honmane, S. M.; Dange, Y. D.; Osmani, R. A. M.; Jadge, D. R. Asian J. Pharm., 2017, 11 (3), pp 479488.

12. Ansari, M. S.; Patel, D. K.; Kesharwani, R.; Kumar, V. J. Drug Delivery Ther., 2017, 7 (4), pp 20-33 (http://dx.doi.org/10.22270/jddt.v7i4.1487). 
13. Gordon, K. C.; McGoverin, C. M. Int. J. Pharm., 2011, 417 (1-2), pp 151-162 (https://doi. org/10.1016/j.ijpharm.2010.12.030).

14. McGoverin, C. M.; Rades, T.; Gordon, K. C. J. Pharm. Sci., 2008, 97 (11), pp 4598-4621 (https://doi. org/10.1002/jps.21340).

15. Kwok, K.; Taylor, L. S. Vib. Spectrosc., 2012, 61, pp 176-182 (https://doi.org/10.1016/j. vibspec.2012.02.018).

16. Franzen, L.; Selzer, D.; Fluhr, J. W.; Schaefer, U. F.; Windbergs, M. Eur. J. Pharm. Biopharm., 2013, 84, pp 437-444 (https://doi.org/10.1016/j.ejpb.2012.11.017).

17. Scoutaris, N.; Vithani, K.; Slipper, I.; Chowdhry, B.; Douroumis, D. Int. J. Pharm., 2014, 470 (1-2), pp 88-98 (http://dx.doi.org/10.1016/j.jpharm.2014.05.007).

18. Vajna, B.; Farkas, I.; Szabo, A.; Zsigmond, Z.; Marosi, G. J Pharm Biomed Anal., 2010, 51 (1), pp 3038 (http://dx.doi.org/10.1016/j.jpba.2009.07.030).

19. Kwok, K.; Taylor, L. S. J Pharm Biomed Anal., 2012, 66, pp 126-135 (http://dx.doi.org/10.1016/j. jpba.2012.03.026).

20. Kalantri, P. P.; Somani, R. R.; Makhija, D. T. Der Chemica Sinica, 2010, 1 (1), pp 1-12.

21. Rebiere, H.; Martin, M.; Ghyselinck, C.; Bonnet, P. A.; Brenier, C. J Pharm Biomed Anal., 2018, 148, pp 316-323 (https://doi.org/10.1016/j.jpba.2017.10.005).

22. Reddy, B. S.; Prasad, S. N. V. L. V.; Sekhar, R. R. C.; Bhaskar, V. WO 2010/120750 A2, October 21, 2010, Dr. Reddy`s Laboratories LTD, Andhra Pradesh (IN).

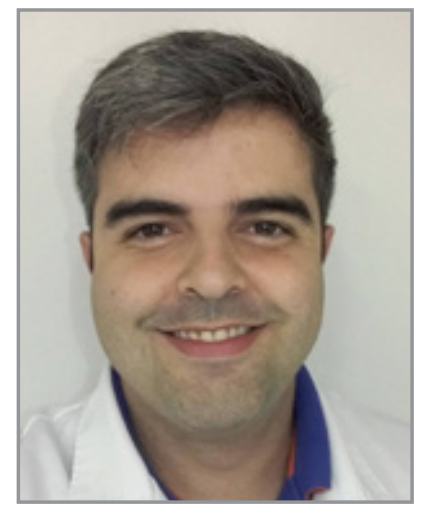

Renan M. B. Dezena Sciences from Pontifical Catholic University of Campinas (PUC-Campinas), Brazil (2010), and Specialization in Management of Research and Development of Drugs through the Institute of Sciences, Technology and Quality (ICTQ), Brazil (2014). He has 11 years of experience in the Pharmaceutical Industry with background in the Departments of Production, Quality Control and Research \& Development. Perform Preformulation Studies related to the development of pharmaceutical products through the following analytical techniques: Mass spectrometry (LC-MS/MS), Infrared Spectroscopy (MIR and NIR), Ultraviolet Spectroscopy, Liquid Chromatography (HPLC and UPLC), Gas Chromatography (GC-MS), Differential Scanning Calorimetry (DSC), Thermogravimetric Analysis (TGA), X-Ray Powder Diffraction (XRPD), Optical Microscopy, Particle Size Distribution by Laser Diffraction, Confocal Raman Microscopy, Nuclear Magnetic Resonance Spectroscopy, Zeta Potential and Dynamic Light Scattering.

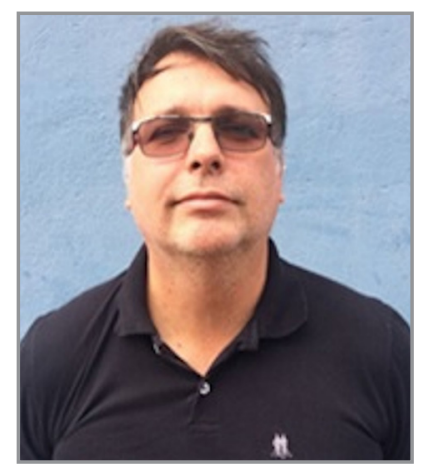

José dos Santos Malta Jr graduated in pharmacy in 1993 and worked at the Analytical Instrumentation Center of the University of São Paulo - Central Analítica, until 1996. He was an analytical researcher at the Cristália Laboratory from 1996 to 2004. From 2005 to the present he is the Pre-formulation Laboratory Manager at EMS SA. 

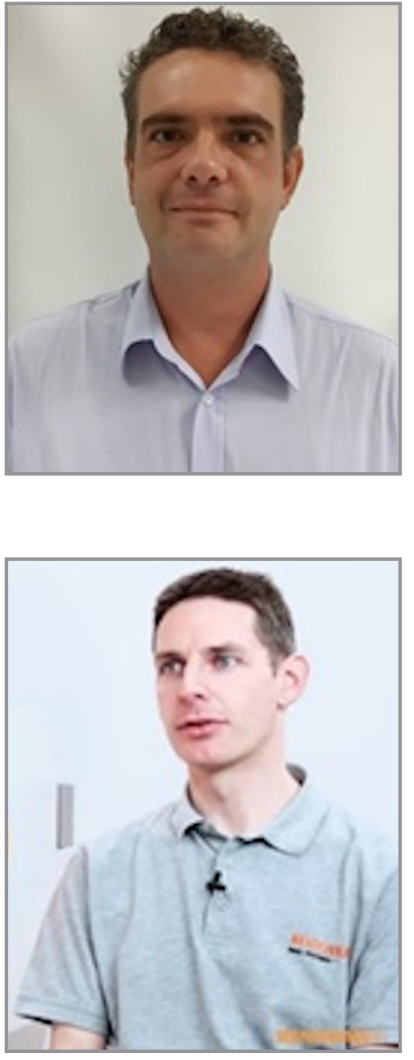

Fábio Preto de Godoy graduated in Chemistry at the Institute of Chemistry, University of São Paulo (2004) and specialized in Industrial Administration from Fundação Carlos Alberto Vanzolini, Polytechnic School, University of São Paulo (2007). He has experience in Vibrational Spectroscopy and works with Infrared and Raman Spectroscopy. He is a Product Development Manager at the Renishaw Company, with experience in strategic sales plan for South America, preparation and presentation of projects, customer management at universities, research institutes and industry, participation in scientific congresses, organization of workshops, prospecting for new customers, technical visits, consulting application, technical and operational training of clients, training and management of representatives in Brazil and South America.

Tim Smith is graduated in Chemistry at the University of East Anglia, Norwich, UK. He is Applications Manager at the Renishaw Company, with 21 years of extensive experience in advanced applications of Raman spectroscopy and responsible for applications of Raman spectroscopy, Raman imaging techniques, Pharmaceutical drug and formulation analysis, Marketing and application development for new projects. 